\title{
Greenhouse Effect International Cooperation: Rethink Kyoto Protocol
}

\author{
Longlong Guo \\ Department of Biotechnology, Chemistry and Environmental Engineering \\ Sohngaardsholmsvej 57, 9000 Aalborg, Denmark \\ Tel: 0045-2992-3337_E-mail: guo@bio.aau.dk, harry99211@gmail.com
}

\author{
Hongbo Ma \\ Tangshan Kailuan Oriental Power Co. Ltd \\ A-601, ShiJi HuaTing, XinHuaDao, Tangshan city, Hebei, China \\ Tel: 86-315-325-2787_E-mail: mahongbo777@hotmail.com
}

\begin{abstract}
The greenhouse gas emission has the closed relation with the economic growth in the every country, therefore reducing the greenhouse gas emission level or decreasing its increasing speed affect the national economic growth. If developed countries take the unconcern of the developing countries as the reason, they didn't adopt any measurements. If developing countries think the developed countries must be responsible for the climate change, they reject any action, also including Kyoto protocol. Every country governments lack national support so that the promise can't be realized in the international negotiates. Whether Kyoto Protocol finally can formally become effective depends on the economy and sustainable development.
\end{abstract}

Keywords: Kyoto Protocol, Nation Framework Convention on Climate Change(UNFCCC), Sulfur oxides, Nitrogen oxides, Hydrocarbons, Carbon monoxide, Clean Development Mechanism(CDM), Montreal Protocol, Semi-governmental organization, Non-government organizations(NGOs)

\section{Introduction}

Environmental issues emerged in the late twentieth century as a major focus of international concern and activity. Understanding the causes and impacts of global environmental change is an urgent task(Owen Green, 2005). Since industrial revolution, in the production of industry and agriculture the greenhouse gas emission from human activities has already leaded on the greenhouse gas concentration increased rapidly, the greenhouse effect causes serious outcome to the littoral and ecosystem. Global warming or the greenhouse effect is the prototype of the global commons issue. All nations are affected by the earth's climate system, and broad international cooperation is required to mitigate the threat of global warming(Gareth Porter, Janet Welsh Brown and Pamela S. Chasek, 2000). In order to 21st century's earth eliminating the threatens of the climate change, in the December 1997, the United Nation Framework Convention on Climate Change (UNFCCC) was held in Tokyo in Japan and generated Kyoto Protocol which restricts the greenhouse gas discharge from developed countries and restrains the global warming.

\section{China Case Study}

In China human activity is the main roots of the air pollution. Such as intensive population, city dimension expended, city-industry distribution irrationality, and low efficiency environment management, etc; these factors increase a great deal of unstable component into the air. In contrast to the natural sources of air pollution, which is like carbon monoxide from the breakdown of methane; hydrocarbons in the form of terpenes from pipe trees, and hydrogen sulfide and methane from the anaerobic decomposition of organic matter, human activities sources are like total suspended particulates, sulfur oxides, nitrogen oxides, hydrocarbons and carbon monoxide. The use of fossil fuels is the dominative factor of the air pollution for heating and cooling, for transportation, for industry, and for energy conversion, and the incineration of the various forms of industrial, municipal, and private waste all contribute to the pollution of the atmosphere, so do the handling and processing operations of various and sundry industries. The sources of these pollutants are so numerous and they have been categorizing into four main groups. Mobile transportation is like motor vehicles, aircraft, railroads, ships and the handling or evaporation of gasoline; stationary combustion is like residential, commercial and industrial power and heating, including stream-powered electric power plants; industrial processes is like chemical, metallurgical and pulp-paper industries and petroleum refineries; and solid waste disposal is like 
household and commercial refuse, coal refuse, and agriculture burning.

China's air pollution is the coom type. Northward situations overweigh southward; middle-small cities' pollution tendency is more than big cities; coal production area is higher than without coal production area; winter situations exceed summer; morning and evening overweigh midday. At present coal is the dominative energy consumption, amounting to $75 \%$ of its total energy consumption. Coal combustion, in which mass pollutants of dust, carbon dioxide, etc are produced, is the main cause to trend to the increasingly serous air pollution in China. For example climate change is spreading and threatens China and circumjacent countries. At present China takes economic development as its top priority of the short and medium term, in order to reduce the greenhouse gas emissions, China has encouraged the energy saving, the use of clean energy and supporting the development of energy efficiency and renewable energy. China has played an important role and takes a proactive attitude towards the global efforts for climate changed control. However it reiterates that as a developing country, it should focus on economic development and reducing the number of people living in poverty and not be subject to binding emission reduction obligations under world climate change framework(Hohne Niklas and Dian Pylipsen and Simone Ullrich and Kornelis Blok, 2005). How to keep the balance between reducing the greenhouse gas emission and protecting environment towards the sustainable development? How to implement Kyoto Protocol? How to cooperate with developed countries? ... These questions are the present challenge to China.

\section{International society feedback}

At the core of the 1997 Kyoto Protocol are legal binding commitments b developed countries to limit greenhouse gas emissions. The EU, USA, and Japan respectively committed themselves to reduce their annual greenhouse gas emissions by December 2008 to 8. 7. and 6 percent less than 1990 levels. Prospective EU members such as Poland adopted EU targets; while Russian, Ukraine, and New Zealand agreed to stabilize their emissions at 1990 levels and Australia, Iceland, and Norway managed to negotiate limited increased in their permitted emissions. These commitments refer to net emissions, so that greenhouse gas emissions may be offset by absorption of such gases in sinks such as afforestation projects. Overall these commitments would imply a 5 percent reduction in greenhouse gas emissions in industrialized countries.

According to the Kyoto Protocol, the developed countries must provide the financial support, and cooperate with the aspects of science and technology. It also allows the developed countries to exchange part of their national emission allowances and establish the Clean Development Mechanism (CDM) that allows developed countries to obtain emission credits for financing approved climate friendly projects in developing countries. This kind of plan requests to set up the discharge quantity in a country. These countries that didn't use up the quantity can sale a part to the other countries. Therefore the countries with the discharge surplus must reduce the discharge quantity; the countries with enough quantity can get some benefit in the financial aspect. In the Kyoto Protocol, the set quantity has set to the developed countries, namely equal the reducing discharge promise. This is based on the cost benefit to decrease the greenhouse discharge quantity.

From the international political point, Kyoto Protocol is one of the most complicated multilateral negotiate in the present international social. For example, EU want to strive for the $15 \%$ of reducing discharge goal, but USA just only keep the stable discharge from 2008 to 2012 . Whereas the point of departure is different, each country achieves the agreement with a certain law sanction.

From the economic point, Kyoto Protocol focus on the cost benefit, but the price of implementing Kyoto Protocol is quite expensive. Clinton government estimates GDP would be increased by $0.5 \%$ per year. The research from the scientist states implementing Kyoto Protocol can decrease the $0.2 \%$ to $2 \%$ of GDP to USA, EU and Japan. Through a great of discharge trade, the loss is $0.1 \%$ to $0.3 \%$ (Michael Grubb et al, 1998). This numeric is negligible, but the economists warn: from 2008 to 2012 if USA reduces 35\% of the discharge quantities of carbon dioxide, the world economy will turbulence(Donald A. Carr and Willian 1. Thomas, 1998).

Kyoto Protocol announced the country includes the 55\% discharge quantity of the total greenhouse gas; the country can become effective by 55 countries authorized. China in May 1998 subscribed the Kyoto Protocol and approved the protocol in the August 2002. EU as well as member country approved the Kyoto Protocol in 31st May 2002. Till to the November 2004, 127 countries has approved the Kyoto Protocol, unfortunately USA that occupies the 25\% discharge quantity of total greenhouse gas approved it in the November 1998, but Bush Government rejects the authorize because reducing discharge quantity would affect the USA economy and developing countries also would bear the reducing discharge incumbency. Due to the USA toughness attitude, Kyoto Protocol is approved filling with difficult and can't become effective.

\section{Greenhouse discharge and climate change}

It has the closed relation between greenhouse gas discharge quantity and economic growth in a country. In terms of stipulated range, reducing greenhouse gas discharge or catabatic its increased speed will affect the GDP rising. 


\subsection{Political balk}

The studies of environmental dynamics and politics of environmental regulation can't be understood without approaching both the physical and the social discursive dimensions of environmental problems, their origin, definitions and the responses decided(Jesper Holm). The political problem is the main balk to approve Kyoto Protocol. From the related political problems looking, Kyoto Protocol was approved by the 55 countries and became effective after 90 days. These 55 countries at least discharged the $55 \%$ carbon dioxide discharge of total greenhouse gas compared with 1990. It said Kyoto Protocol that becomes effective must get the reorganization by majority countries. From the past reporting, the process is difficult. To the 04-05-1999, 84 countries had subscribed Kyoto Protocol, but only 8 countries approved the protocol. Almost countries put up acute attitude. Such as EU as a whole, wouldn't approve it before USA and Japan approved it. Furthermore USA senate also wouldn't pass it, unless pivotal developing countries would take the worth valuable action. These pivotal developing countries are Argentina, China, Brazil and India. Though USA subscribed Kyoto Protocol after Argentina and Kazakhstan announced they will bear the incumbency, approving it is very difficult in the future.

Western developed countries are based on the standpoint of worth valuable action from developing countries to consider whether approve Kyoto Protocol or not. The reason is very simple: from past 10 years experience, developing countries lack the strong implementation mechanism from the self country, the result is the government just owns the nominal power, referring to the environmental problem is also like this. Therefore government expresses the willing to carry out the protocol, the country can't be realized any agreements without enough system framework.

The developing countries think the developed countries must take the action firstly, shouldn't force some unreasonable incumbency to the developing countries. This notion can be understood. Forcing developing countries to bear incumbency of volunteer characteristics not only can't achieve the forecast purpose, but also destroy the foreign relations. But then developing countries need consider the long term outcome of preventing strategies. Forecast statement, the greenhouse gas discharge from developing countries will last enhancement, and easily receive the harm of climate change compared with developed countries(IPPC, 1998). According to the background how do the developing countries put the problems of development and which price development into the agenda? In addition it needs the public predication to solve these problems.

Maybe oppugn mentioned, can't the political balk be overstep? Some governments think it optimism. Clinton emphasized we can't take the action after the protocol was approved. If the industry accepts the sign to start to invest new technology; if EU can encourage constituting the strategy of reducing greenhouse gas discharge, in the few years later, Kyoto Protocol will be approved completely.

\subsection{Emission trade}

In the essential discharge trade can't realize the reducing greenhouse discharge. It is difference with the supervision and verified check. It was decided by scientist and policy makers through innovation methods to distribute the discharge quantity to each country and permit they can trade each other. These problems are very complex. Kyoto Protocol attempts to distribute the right in the developed countries, and it is very outrage to the developing countries. Cooper in 1998 forecasted this is a long term problem. Distributing the discharge quantity is a method to solve the problems, but according to the Kyoto Protocol promise, it can't be implemented because of the distribution right. (Richard N. Cooper, 1998) In 1993 Bodansky stated on the one hand, if the purpose considering GDP per capital or per unit put in the global discharge level, like USA with high per capital must reduce the discharge greatly, and affects the economic growth. This kind of purpose can't be realized in the political aspect. On the another hand, if the discharge purpose can be accepted by USA, low discharge countries will also rise the discharge quantity equal to the USA level. The result is global discharge rising greatly(Bodansky, 1993).

\subsection{Public participation}

The worsening trend for a long term has increased the public participation environmental awareness. Government departments have realized that environmental pollution can't be solved by relying only on laws and administrative interventions. When its economic strength and science and technology still remained at a low level, active public participation in environmental protection could be more effective at a lower cost (Zhanglei, 2001). The participation is like individuals, student group, social groups, and semi-governmental organization. Particularly in the recent years, various public media about the individual action and social organization action has been increasing. Under the advancing environmental awareness, the domestic environmental Non-government organizations (NGOs) play a limited role, but the mass media have increasingly treated the environmental issues with the approval of the central government. Public participation has gained the significant success, but intervention limitation reduces the public participation efficiency. Efficiency organized the public participation groups is the one of the important tools to solve the environmental problems. At the same time, the government should not only cooperate with them, but support the finance assistance and give the right to them. 
If the concern from the region is so limited, the national policy is like nominal, and foreign relations are flatulent. Within Europe whether the measurement of reducing discharge can be accepted or not by public. Negotiate official from Europe, USA, Japan think to the deep influence reducing discharge measurement they just get a limitation support from the self country 21 . The early researches show in the majority developing countries, the problem of climate change at all isn't being lined in the national agenda. In some islet countries the climate change has lined in the national agenda, but they almost can't reduce the few discharge.

Fortunately, it has worry, but also has active activity. Some industry is taking action to reduce the discharge. General motors developed a natural gas shift plan to reduce discharge. The academia people are researching to bring forward mode and approach with perfecting climate change management system. NGOs also take part in this activity.

\section{Conclusion}

Kyoto Protocol becoming effect has difficulty, but we can believe whether Kyoto Protocol finally can be approved or not, it depends on the relation between economic growth and sustainable development. If present or future USA president can insure to approve Kyoto Protocol, or EU approves it and obtains a great public support, other developed countries and developing countries also do it like this. Whatever happens, Montreal Protocol (16-09-1987) on Substances that deplete the ozone layer and the on-going negotiations for preparing the framework convention on climate change, the subscription process is like this. If the measurement is right, protecting climate is profit, benefit and high quality life standard.

\section{References}

Bodansky. (1993). The United Nations Framework Convention on Climate Change Regime, page 513.

Climate Change 1995: Economic and Social Dimensions of Climate Change, Cambridge University, chapter 8 and chapter 9, page 263 to 265 .

Clinton Presents Emission Plan' International Herald Tribune, page 3, 23-10-1997.

Clinton Presents Emission Plan' International Herald Tribune, page 3, 23-10-1997.

Clinton Presents Emission Plan' International Herald Tribune, page 3, 23-10-1997.

Donald A. Carr and Willian 1. Thomas (1998). The Kyoto Protocol and US Climate Policy: Implications for American Industry, page 191 to 201.

Environment Minister Council (1997): the conclusion of climate change, EU Minister Council, 001997.

Environmental Taxes: Recent Developments in China and OECD Countries, Organization For Economic Co-operation and Development, 1999.

Gareth Porter, Janet Welsh Brown and Pamela S. Chasek. (2000). Global Environmental Politics, third edition, Westview Press, 2000, page 112.

Gupta and van der Grijp. (1999). Leadership in the Climate Change Regime.

Hohne Niklas and Dian Pylipsen and Simone Ullrich and Kornelis Blok. (2005). Options for the Second Commitment Period of the Kyoto Protocol, Germany, page 8.

IPPC. (1998). The Regional Impact of Climate Change: An Assessment of Vulnerability, Cambridge University Press.

Jesper Holm: Building Transdiplinary Environmental Studies, Depart. Of Environment, Technology and Social Studies, Roskilde University, Denmark, page 3.

Michael Grubb et al. (1998): Te Kyoto Protocol, Earthscan, London, chapter 5.

Owen Green. (2005). Environmental issues, Oxford University Press, 2005.

Richard N. Cooper. (1998). Toward a Real Global Warming Treaty' Foreign Affairs.

The United Nations Framework Convention on Climate Change, item 3.

The United Nations Framework Convention on Climate Change: Kyoto Protocol, attachment B. Greene, Owen. (2005): Environmental Issue. Oxford University Press, page 471.

The United Nations Framework Convention on Climate Change: Kyoto Protocol, item 2 and item 12. Greene, Owen. (2005): Environmental Issue. Oxford University Press, page 471.

The United Nations Framework Convention on Climate Change: Kyoto Protocol, item 24.

Zhanglei, (2002). Ecological Industrialization in Chinese Small Towns. Wageningen University. 